\title{
Advances in the prevention and treatment of lung cancer
}

\author{
${ }^{1}$ PS Hodkinson, ${ }^{2} \mathrm{~T}$ Sethi \\ ${ }^{1}$ Clinical Lecturer in Respiratory Medicine, University of Edinburgh; ${ }^{2}$ Professor of Respiratory Medicine, King's College Hospital, London, UK
}

\begin{abstract}
Lung cancer remains the most common fatal malignancy in the Western world. Survival rates have only improved modestly over the past three decades and new approaches are urgently required. It is clear that a concerted effort to reduce cigarette smoking is required. However, about $10 \%$ of patients with lung cancer are never smokers, indicating genetic or other predisposition. Lung cancer screening programmes are being trialled to target high-risk populations. Genetic strategies will provide new methods for screening and predicting response to treatment. Current therapy for lung cancer has reached a plateau and novel agents have shown modest clinical efficacy. Understanding the mechanisms by which chronic inflammatory disorders such as chronic obstructive pulmonary disease contribute to lung cancer development will help to identify new biological targets and biomarkers of early disease. This review focuses on recent advances in lung cancer prevention and treatment.
\end{abstract}

KEYWORDS Biological therapy, genetics, inflammation, lung cancer, screening, smoking

\author{
Correspondence to T Sethi, \\ Department of Respiratory \\ Medicine and Allergy, King's \\ College Hospital, Denmark Hill \\ Campus, Bessemer Road, \\ London SE5 9RS, UK
}

tel. $+44(0) 2032993165$ e-mail tariq.sethi@kcl.ac.uk

DECLARATION OF INTERESTS No conflict of interests declared.

\section{INTRODUCTION}

Lung cancer accounts for more than 30,000 deaths each year in the UK.' The most frequent histological type is non-small cell lung cancer (NSCLC), which includes adenocarcinoma and squamous cell carcinoma. ${ }^{2,3}$ These tumours can present with locally confined disease and therefore curative surgery or radiotherapy, possibly in combination with chemotherapy, are the treatments of choice. 4.5 Depending on the stage, the survival rates for surgically resected NSCLC vary from $25 \%$ to $65 \%$ at five years. ${ }^{6.7}$ In contrast, survival rates in advanced NSCLC are poor (5-10\% at five years). ${ }^{7}$ Fewer than one in three patients is suitable for radical surgery and therefore overall ten-year survival remains less than $10 \% .{ }^{1,7}$

Despite advances in diagnosis and treatment, survival figures for lung cancer have only improved modestly in the past two decades. ${ }^{7}$ This has led many clinicians to call for new research with the aim of developing novel and effective therapeutic strategies. Improved understanding of the molecular biology of lung cancer will lead to better therapy and the identification of new risk factors and early diagnostic markers. This review focuses on the recent advances in this field, with a specific focus on NSCLC.

\section{LINK TO CIGARETTE SMOKE}

A landmark case-control study by Doll and Hill published in 1950 investigated the link between tobacco smoke and lung cancer. ${ }^{8}$ It recruited patients with carcinoma of the lung, stomach, colon or rectum admitted to 20 London hospitals. Patients were then interviewed with respect to smoking habits and, for each lung cancer case identified, a control from the same hospital of the same sex and similar age (within five years) but not suffering from cancer was also interviewed. The crucial result from this study was that cigarette smoking had a direct association with lung cancer and that smoking habits were formed before the onset of the disease, suggesting causality. ${ }^{8}$ Subsequently cigarette smokers were shown to have about 20 times the risk of lung cancer as life-long nonsmokers. ${ }^{910}$ Passive exposure to cigarette smoke resulted in positive urine tests for carcinogens specific to tobacco and is associated with a higher cumulative risk of lung cancer. ${ }^{11,12}$ The clear association between lung cancer and smoking indicates that trends in lung cancer epidemiology closely follow changes in tobacco consumption, with a lag time of 25-30 years. ${ }^{13}$ Future trends in lung cancer will therefore be shaped by the increase in female smokers in the past few years and the higher prevalence of tobacco use in lower socioeconomic groups. ${ }^{14}$

\section{Smoking cessation reduces lung cancer risk}

Data from the past ten years demonstrated that people who quit smoking have a reduced risk of lung cancer compared with those with a continued smoking habit, although the risk does not return to that of life-long non-smokers, even after 30 years of abstinence. ${ }^{15,16} \mathrm{~A}$ case-controlled study conducted between 1988 and 1993 showed that the risk of death from lung cancer in male ex-smokers was approximately $5 \%$, compared with almost $16 \%$ in males of the same age who continued to smoke. This effect was strongest if smokers quit at the age of 30 but was still significant up to the age of $60 .{ }^{16} \mathrm{~A}$ recent meta-analysis showed that continuation of smoking after diagnosis is associated with an increased risk of tumour recurrence and death (all causes) in early-stage lung cancer. ${ }^{17}$ Targeting current smokers to actively promote smoking cessation is therefore central 
to lung cancer prevention and to reducing the risk of recurrence after curative treatment.

\section{Advances in smoking cessation}

Cigarette smoke-related cancer remains a significant health burden, despite changes in government policy and public health campaigns. This is in part due to nicotine addiction promoting continued smoking and thus exposure to inhaled carcinogens. ${ }^{18}$ Until recently, smoking cessation therapy has focused on counselling, nicotine replacement and bupropion. Unfortunately, long-term cessation rates are poor (approximately twice placebo). ${ }^{19}$

Recent work has advanced our knowledge of nicotine addiction and produced targeted drug therapy to promote smoking cessation. In 2006, a clinical trial compared varenicline, a partial agonist at the $\alpha 2-\beta 4$ nicotinic receptor, with sustained release bupropion or placebo. Importantly, 12 weeks of varenicline therapy produced significantly greater continuous abstinence rates compared with the other two interventions..$^{20} \mathrm{An}$ additional study demonstrated that prolonged therapy with varenicline ( 24 weeks) improved abstinence rates compared with placebo, even when the drug was stopped, ${ }^{21,22}$ although long-term quit rates remained low. These studies resulted in the approval of varenicline for use in smoking cessation. It is also important to note the key role of smoking cessation services in coordinating cessation therapy and improving quit rates. ${ }^{23}$

It is clear that further research is required into the mechanisms of nicotine addiction. A new report highlights a nicotine addiction locus on chromosome 15q24-25, which includes the $\alpha 5-\alpha 3-\beta 4$ nicotinic receptor gene cluster. ${ }^{24} \mathrm{~A}$ polymorphism, which alters an amino acid in this nicotinic receptor, is associated with lung cancer and chronic obstructive pulmonary disease (COPD).$^{24}$ It is hoped that this kind of research will identify novel genes that promote nicotine addiction and thus reveal new targets for drug therapy. The future may involve assessing 'addiction' genes in smokers to allow individualised therapy.

\section{GENETIC RISK FACTORS}

Approximately $10 \%$ of lung cancers arise in life-long nonsmokers. ${ }^{25}$ This group accounts for nearly 3,000 deaths each year in the UK..$^{25}$ The development of lung cancer in non-smokers cannot be solely attributed to passive smoking or atmospheric pollution, suggesting the existence of genetic and/or other risk factors. This hypothesis is supported by the observation that smokers who have a first-degree relative diagnosed with lung cancer before 50 years of age have a higher risk of developing lung cancer than those with no family history. ${ }^{26}$

Bailey-Wilson and colleagues' linkage analysis of 52 families with three or more individuals affected by respiratory tract malignancy showed that susceptibility to lung cancer maps to a locus on chromosome 6q2325. ${ }^{27}$ Detailed mapping of this region revealed a potential candidate gene, although its function is unknown. ${ }^{28}$ Genome-wide association studies have also identified loci on chromosomes 5p15, 6p2I and 15q25 that are associated with lung cancer. ${ }^{29,30}$ Of particular interest, 15q25 contains three cholinergic nicotine receptor genes and variations in these genes may contribute to lung cancer risk independent of effect on nicotine addiction. ${ }^{31}$ These loci only account for $10 \%$ of familial lung cancer risk and stratification of current and ex-smokers by number of risk variants shows that smoking is the predominant risk factor. ${ }^{32}$

Other approaches to identify genetic factors associated with lung cancer have focused on differential gene expression profiles from airway epithelium of current and never smokers and the sequencing of lung cancer genomes. ${ }^{33,34}$ It is anticipated that research of this type will identify at-risk populations for screening, define markers of early disease and suggest novel targets to prevent the carcinogenic effects of tobacco smoke.

\section{LUNG CANCER SCREENING}

Screening for lung cancer is an attractive option. Symptoms caused by lung cancer occur at a late stage as the tumour invades local structures or spreads to distant sites. Thus, the majority of patients present with advanced disease.' Early-stage lung cancer has a better survival rate, primarily as a result of response to treatment and therefore identification of small lung tumours before symptoms are present may greatly affect lung cancer survival. ${ }^{7}$ Several challenges need to be addressed before a successful lung cancer screening programme can be established: defining a screening method, determining the population for screening and developing a pathway for follow-up of pulmonary nodules.

\section{Chest X-ray and computed tomography screening}

Initial screening programmes in lung cancer using chest radiographs and/or cytological analysis of sputum in male smokers have produced disappointing results. ${ }^{35}$ Computed tomography (CT) screening may be a better technique as it is able to detect lung parenchymal changes before they are apparent clinically or on chest $X$-ray. Several lung cancer screening trials using low-dose CT showed that malignant tumours can be detected at an earlier stage than by clinical assessment. ${ }^{35-39}$ However, these trials were not controlled in design and therefore effect on mortality is difficult to determine. In addition, these studies showed high false positive rates and low rates of detection of incident cases of lung cancer..$^{35}$ To address these issues, randomised controlled trials of low-dose CT in lung cancer screening are being conducted. Designed to compare the effect of screening with low-dose CT or chest X-ray on lung cancer 
mortality, the largest of these studies recruited more than 50,000 patients in the US between 2002 and 2004. The last round of screening was carried out in 2007 and an overview report has been published this year. ${ }^{39}$ Smaller European studies have reported preliminary results on prevalence of lung cancer at baseline screening but have yet to complete. ${ }^{40,41}$

Screening programmes are not without inherent difficulties, some of which are specific to lung cancer. Many of the reported screening studies show that uptake by the 'at-risk' population is low and methods for recruitment are inefficient. ${ }^{42}$ In addition, the prevalence of pulmonary nodules detected by $\mathrm{CT}$ is high in the 'at-risk' population. ${ }^{43}$ However, the majority of nodules are benign, even in smokers, raising concerns about over-investigation of potential malignancy. ${ }^{44}$ Finally, although some screening studies have suggested improvements in lung cancer mortality in the screened population, other investigators have suggested that this may simply be due to detection of cancer earlier within its natural history or so-called 'lead-time' bias. ${ }^{45}$

\section{UK lung screening trial}

To address these issues Baldwin et al. have recently described the UK lung screening trial (UKLS). ${ }^{46}$ This will recruit 28,000 patients from seven centres in the UK with $\geq 5 \%$ lung cancer risk within five years, determined using a well-established model of lung cancer risk (Liverpool Lung Project risk model). Patients will be randomised to either low-dose CT screening or no screening with a ten-year follow-up. The study will employ a single-screen design with a nodule management protocol based on volumetric analysis and nodule characteristics, which determines referral to the multidisciplinary team or CT follow-up. It also defines a new protocol for the follow-up of pulmonary nodules. It is hoped that this study will not have the problems of longterm compliance as it employs a single screen technique and may prove to be cost-effective as it targets a highrisk population. It is highly likely that routine CT screening in the UK will wait until the results of this trial.

\section{ADVANCES IN THE STAGING OF NSCLC}

The primary influence on lung cancer treatment decisions by the multidisciplinary team is the stage of the tumour at diagnosis. The Tumour Node Metastasis (TNM) classification of NSCLC, which originated in 1974, has recently been revised. For the first time, this revision (the seventh edition) is based on analysis and validation of outcome data from a large international database of lung cancer cases. ${ }^{47}$ There have been several important alterations in the descriptions of the $T$ and $M$ groupings to reflect differences in patient prognosis, which are summarised in Table I. Following careful analysis, the $\mathrm{N}$ descriptor has remained unchanged (N0-3). Although these new TNM subgroups have resulted in a more complex
TABLE I Summary of important changes in the seventh edition of the Tumor Node Metastasis (TNM) classification

\begin{tabular}{|l|}
\hline T descriptor \\
\hline $\begin{array}{l}\text { A size cut-off of } 2 \mathrm{~cm} \text { divides TI tumours into 'a' and 'b' } \\
\text { subcategories. }\end{array}$ \\
\hline $\begin{array}{l}\text { A size cut-off of } 5 \mathrm{~cm} \text { divides T2 tumours into 'a' and 'b' } \\
\text { subcategories. }\end{array}$
\end{tabular}

Tumours with additional tumour nodules in the same lobe as the primary tumour are now designated T3 rather than T4.

Additional tumour nodules in other ipsilateral lobe(s) are reclassified from $\mathrm{MI}$ to $\mathrm{T} 4$.

\section{M descriptor}

Tumours associated with additional tumour nodules in the contralateral lung are classified as Mla.

Mla category now includes lung tumours with malignant effusion involving the pleural or pericardium (reclassified from T4).

MIb subcategory includes those tumours with distant/ extra-thoracic metastases.

definition of the stage groups (I-IV), the seventh edition classification is widely accepted as a more evidencebased system for the basis of treatment decisions.

Staging techniques for lung cancer have also advanced in the past decade, including more sophisticated imaging such as I8F-deoxyglucose positron emission tomography (FDGPET). This technique is now widely available to cancer centres and has been shown to accurately stage lung cancer and prevent unnecessary radical treatment. ${ }^{48}$ However, its applicability is limited by false positive and negative results ${ }^{48}$ and confirmation by histology is often necessary.

Minimally invasive staging techniques have progressed significantly, particularly in the field of endobronchial ultrasound (EBUS). Endobronchial ultrasound allows almost complete staging of mediastinal lymph nodes, can be carried out as a day case and has a high sensitivity and specificity. ${ }^{49}$ It is now often the first-choice diagnostic and staging technique for suspected NSCLC with an involvement of the mediastinal nodes on imaging (CT or FDG-PET) and can prevent unnecessary thoracotomy. ${ }^{50}$ Endobronchial ultrasound is, however, limited to fine needle aspirate (FNA) samples, which may not be sufficient for the assessment of biomarkers of treatment response. This issue is being addressed by research on ribonucleic acid extracted from EBUS-FNA samples. ${ }^{51}$

\section{ADVANCES IN CHEMO- AND RADIOTHERAPY}

\section{Adjuvant therapy}

Surgical resection remains the recommended treatment modality for patients with early stage (I-II) disease, as it produces the best survival outcome. ${ }^{52}$ Radical radiotherapy should be considered for patients who have potentially resectable disease but cannot undergo surgery for other reasons. ${ }^{53}$ Despite radical surgery, five- 
year survival rates are suboptimal, often due to tumour recurrence at untreated sites. This has led to considerable research into the effectiveness of adjuvant therapy for resected NSCLC. In an analysis of the five largest trials of adjuvant cisplatin-based chemotherapy using individual patient data, Pignon et al. showed an absolute survival benefit of approximately $5 \%$ at five years with platinumbased chemotherapy, irrespective of the second drug in the regime. ${ }^{54}$ They also concluded that the benefit was greater for those with stage II or III disease. As a result, the National Institute for Health and Clinical Excellence (NICE) guidelines now suggest considering post-operative chemotherapy for patients after complete resection. ${ }^{55}$

In contrast, post-operative radiotherapy (PORT) remains controversial. Analysis of randomised controlled trials and national databases has not suggested an overall survival benefit with PORT, although some data suggest a prognostic benefit in those patients with N2 disease. ${ }^{56-58}$ The ongoing Lung Adjuvant Radiation Trial aims to assess PORT in patients with resected N2 NSCLC. ${ }^{59}$ Postoperative radiotherapy may also be of possible benefit in patients with NO disease with incomplete resection margins..$^{60,61}$ Combined post-operative chemo- and radiotherapy has also been trialled, with no statistically significant survival benefit and increased side effect profile. $^{62,63}$ In the light of these studies, the NICE guidelines suggest that PORT be considered in patients with incomplete resection. ${ }^{56}$ One of the next challenges for adjuvant therapy trials will be the definition of tumour biomarkers that predict response to treatment to allow oncologists to develop individualised management strategies for patients.

\section{Advanced NSCLC}

Recent advances have been made in the treatment of unresected stage III NSCLC. Analysis of earlier studies showed that the combination of radical radiotherapy and chemotherapy provides a significant benefit in survival compared with either treatment modality alone. ${ }^{64}$ An up-to-date meta-analysis of 19 randomised trials confirmed that combination therapy significantly reduces overall risk of death compared with radiotherapy alone at an increased risk of toxicity. ${ }^{65}$ Furthermore, this publication demonstrated that concurrent chemoradiation provided a significant survival advantage compared with chemotherapy followed by radiation, with an absolute survival benefit at two years of approximately $10 \%{ }^{65} \mathrm{It}$ is likely that advances in this field will come with the development of novel radiation techniques and trials of new chemotherapy agents.

The standard treatment for patients of good performance status with advanced NSCLC (stage IIIB-IV) remains two-agent platinum-based chemotherapy. ${ }^{66,67}$ Recent data from a phase III trial suggest that cisplatin plus pemetrexed has a survival advantage over cisplatin plus gemcitabine for NSCLC with non-squamous histology. ${ }^{68}$
Second-line chemotherapy is increasingly used for patients of good performance status. Phase III trials have demonstrated the efficacy, in terms of survival and quality of life, of single-agent docetaxol or pemetrexed, compared with supportive care, for patients with recurrent or progressive disease. ${ }^{69-71}$ In addition, two phase III trials indicated that patients treated with maintenance docetaxol or pemetrexed following four cycles of platinum-based chemotherapy had improved progression-free survival in comparison with those on best supportive care. ${ }^{72,73}$ Maintenance pemetrexed also improved overall survival. ${ }^{73}$ Despite these advances, fiveyear survival in stage IIIB-IV NSCLC remains very poor, and novel targeted agents are being sought.

\section{GROWTH FACTOR PATHWAYS IN NSCLC}

A major event in malignant transformation is the development of uncontrolled cellular proliferation. A wide range of polypeptide growth factors regulate cell division by binding to receptors that possess intrinsic tyrosine kinase activity. ${ }^{74}$ Mutations in these growth factor signalling pathways have been identified in many cancers and have been the focus for the development of novel therapies. ${ }^{75}$ The best studied of these in lung cancer are the epidermal growth factor receptor (EGFR) and vascular endothelial growth factor (VEGF).

\section{Epidermal growth factor receptor}

The EGFR family (HER I-4) is a group of transmembrane receptors that play a critical role in the pathogenesis of many cancers. ${ }^{76}$ Epidermal growth factor receptor expression is observed in up to $80 \%$ of NSCLC tumours and has been shown in some studies to predict poorer prognosis. ${ }^{77}$ Two groups of agents targeting EGFR have been trialled in lung cancer: monoclonal antibodies blocking ligand-receptor interaction (cetuximab) and inhibitors of the EGFR tyrosine kinase activity (gefitinib and erlotinib). In phase II trials cetuximab was generally well tolerated and could confer survival advantage either as single therapy in patients with previously treated advanced NSCLC or in combination with standard chemotherapy regimes as first-line treatment for advanced NSCLC. ${ }^{78}$ In a phase III trial of EGFRpositive advanced NSCLC (FLEX), cetuximab added to cisplatin and vinorelbine produced a modest survival advantage ( 1.2 months), compared with chemotherapy alone. ${ }^{79} \mathrm{~A}$ recent meta-analysis of four trials concluded that the combination of cetuximab and standard chemotherapy as first-line treatment in advanced NSCLC can improve survival and response rate compared with chemotherapy alone, although the cost-effectiveness has been questioned. ${ }^{80,81}$

Gefitinib and erlotinib have been the primary focus of clinical trials as they can be orally administered. Several phase II studies in advanced NSCLC demonstrated good tolerability, encouraging objective response rates and 
improved quality of life scores with gefitinib. ${ }^{82-84}$ However, several large phase III trials in previously treated and in chemotherapy-naive advanced NSCLC have failed to show an overall survival advantage with gefitinib. ${ }^{85-88}$ This is in contrast to a phase III trial comparing erlotinib with placebo in previously treated stage IIIB/IV NSCLC that indicated a significant survival advantage with erlotinib, ${ }^{89}$ which was subsequently approved as second-line therapy for advanced stage NSCLC.

The results with gefitinib have been disappointing. However, certain patient groups (e.g. adenocarcinoma, female gender, non-smokers) may exhibit better responses to anti-EGFR therapy. ${ }^{90}$ Interestingly, these individuals have the highest rate of EGFR tyrosine kinase mutation." Several small phase II studies of gefitinib in patients with EGFR mutations have shown encouraging progression-free survival times. ${ }^{92}$ The IRESSA Pan-Asia Study (IPASS) trial investigated the effectiveness of firstline gefitinib compared with standard chemotherapy in a patient group $(n=1,217)$ from East Asia with advanced NSCLC (adenocarcinoma histology) and a history of light or no smoking. ${ }^{93} \mathrm{~A}$ total of 437 patients had an evaluation of EGFR mutation. Importantly, the mutationpositive group $(n=261)$ had a significantly better response to gefitinib compared with chemotherapy, whereas this was not the case in the mutation-negative group. This suggests that the assessment of EGFR mutations may be an important biomarker in NSCLC for predicting response to anti-EGFR tyrosine kinase inhibitors. ${ }^{93}$

Another important factor that determines response to these agents is the presence or development of drug resistance. Recognised resistance mechanisms in NSCLC include mutations in KRAS, activation of other additional signalling pathways (e.g. mesenchymal epithelial transition factor) and EGFR mutations (e.g.T790M). ${ }^{94}$ Defining new resistance factors and the design of second-generation inhibitors of EGFR will be the focus of future research.

\section{Angiogenesis and vascular endothelial growth factor}

For a tumour to grow and remain viable, new blood vessel formation is essential. This process, named angiogenesis, is regulated by VEGF and its receptor tyrosine kinases. ${ }^{95}$ High VEGF levels in NSCLC are associated with a poor prognosis, making this signalling pathway an attractive target in NSCLC. ${ }^{96}$ Bevacizumab is a humanised monoclonal antibody that binds and neutralises VEGF. Two phase III trials in advanced NSCLC confirmed that bevacizumab in combination with standard chemotherapy improves objective responses and progression-free survival time compared with chemotherapy alone. ${ }^{97,98}$ However, a significant increase in pulmonary haemorrhage has been observed with bevacizumab.

Several small molecule tyrosine kinase inhibitors have been developed recently that target VEGF and other growth factor signalling receptors, including EGFR and platelet-derived growth factor. Initial phase II trial results have shown some efficacy with these agents in advanced NSCLC.99,100 The results of ongoing phase III trials are awaited.

Growth factor receptor signalling remains an active area of research interest in NSCLC. It is likely that with increased knowledge of these pathways, their activating mutations and downstream components, novel targeted therapies will be developed in the next ten years. Defining markers of treatment response will remain the challenge for the future and will hopefully lead to individualised cancer therapy.

\section{LUNG CANCER AND INFLAMMATION}

The role of inflammation in lung cancer development has been much better understood in the past five years. It is now clear that COPD, even in the absence of cigarette smoking, increases the risk of lung cancer up to five-fold and that treating airways inflammation in COPD with inhaled corticosteroids may reduce the risk of lung cancer. ${ }^{101,02}$ Pulmonary fibrosis is also associated with an increased risk of lung cancer. ${ }^{103}$ In addition, C-reactive protein, a marker of the systemic inflammatory response, has been shown to predict lung cancer risk. ${ }^{104}$ Furthermore, microbial colonisation and associated inflammation in patients with COPD, including exsmokers, may increase the risk of lung cancer. In vivo, infecting the mouse lung with Haemophilus influenzae can produce bronchial inflammation with a pattern similar to COPD and promote lung cancer development. ${ }^{105}$

There is now a growing body of evidence that the processes involved in chronic lung inflammation are shared by those early on in lung cancer development and may in fact promote the growth of established tumours. ${ }^{106,107}$ In studies of lung cancer resections, the tumour infiltrating stroma consisted of a complex reaction of immune cells, fibroblasts, blood vessels and extracellular matrix, with similar features to a chronic wound. ${ }^{108}$ Certain cell types in this infiltrate correlated with patient prognosis, including macrophages and lymphocytes, suggesting an important role in lung cancer pathogenesis. ${ }^{109}$ In a syngeneic mouse model, lung cancer growth was reduced by restricting 'alternative' macrophage activation. ${ }^{110}$ Research defining pathways that regulate lung cancer inflammation may reveal new targets for therapy.

The next ten years will hopefully see a clear understanding of the inflammatory signals involved in early cancer development. This may reveal new markers for lung cancer screening and define targets to prevent or reverse the carcinogenic effects of tobacco smoke. The impact of these advances on lung cancer survival are unlikely to be felt for two to three decades and therefore research into lung cancer screening and treatment must continue. 


\section{CONCLUSION}

Lung cancer continues to cause early death and, despite advances in standard treatment, mortality rates have seen only a modest improvement in the past 20 years. We now need strategies for reducing smoking, preventing the carcinogenic effects of tobacco smoke and detecting lung cancers early in the disease course by targeting at-risk populations. Furthermore, new treatments for lung cancer are required to improve survival after 'curative' radical surgery and in locally advanced/

\section{REFERENCES}

I Ferlay J, Autier P, Boniol $M$ et al. Estimates of the cancer incidence and mortality in Europe in 2006. Ann Oncol 2007; I8:58I-92. doi:I0.1093/annonc/mdl498

2 Harkness EF, Brewster DH, Kerr KM et al. Changing trends in incidence of lung cancer by histologic type in Scotland. Int J Cancer 2002; 102: 179-83. doi:10.1002/ijc. $1066 \mid$

3 Janssen-Heijnen ML, Coebergh JW. The changing epidemiology of lung cancer in Europe. Lung Cancer 2003; 41:245-58. doi:10.1016/ SOI69-5002(03)00230-7

4 Ginsberg MS, Grewal RK, Heelan RT. Lung cancer. Radiol Clin North Am 2007; 45:21-43. doi: 10.1016/j.rcl.2006.10.004

5 Ettinger DS. Overview and state of the art in the management of lung cancer. Oncology 2004; 18:3-9.

6 Smythe WR. Treatment of stage I non-small cell lung carcinoma. Chest 2003;123:181-7. doi:10.1378/chest.123.I suppl.I8IS

7 Molina JR, Yang P, Cassivi SD et al. Non-small cell lung cancer: epidemiology, risk factors, treatment, and survivorship. Mayo Clin Proc 2008; 83:584-94. doi: 10.4065/83.5.584

8 Doll R, Hill AB. Smoking and carcinoma of the lung; preliminary report. Br Med J 1950; 2:739-48. doi: I0.1 I 36/bmj.2.4682.739

9 Crispo A, Brennan P, Jöckel $\mathrm{KH}$ et al. The cumulative risk of lung cancer among current, ex- and never-smokers in European men. Br J Cancer 2004; 91: 1280-6. doi: 10.1038/sj.bjc.6602078

10 Doll R, Peto R. Cigarette smoking and bronchial carcinoma: dose and time relationships among regular smokers and lifelong non-smokers. J Epidemiol Community Health 1978; 32:303-13. doi:10.1136/jech.32.4.303

II Tulunay OE, Hecht SS, Carmella SG et al. Urinary metabolites of a tobacco-specific lung carcinogen in nonsmoking hospitality workers. Cancer Epidemiol Biomarkers Prev 2005; 14:1283-6. doi:I0.I I 58/I055-9965.EPI-04-0570

12 Samet JM, Avila-Tong E, Boffetta $P$ et al. Lung cancer in never smokers: clinical epidemiology and environmental risk factors. Clin Cancer Res 2009; 15:5626-45. doi:I0.I I58/1078-0432.CCR-09-0376

13 Shibuya K, Inoue M and Lopez AD. Statistical modeling and projections of lung cancer mortality in 4 industrialized countries. Int J Cancer 2005; I I 7:476-85. doi:10.1002/ijc.21078

14 Karim-Kos HE, de Vries E, Soerjomataram I et al. Recent trends of cancer in Europe: a combined approach of incidence, survival and mortality for 17 cancer sites since the 1990s. Eur J Cancer 2008; 44:1345-89. doi:10.1016/j.ejca.2007.12.015

I5 Ebbert JO, Yang P,Vachon CM et al. Lung cancer risk reduction after smoking cessation: observations from a prospective cohort of women.J Clin Oncol 2003; 2 I:92I-6. doi: I0.1200/JCO.2003.05.085

16 Peto R, Darby S, Deo H et al. Smoking, smoking cessation, and lung cancer in the UK since 1950: combination of national statistics with two case-control studies. BMJ 2000; 321:323-9. doi:10.1136/ bmj.32I.7257.323

17 Parsons A, Daley A, Begh R et al. Influence of smoking cessation after diagnosis of early stage lung cancer on prognosis: systematic review of observational studies with meta-analysis. BMJ 2010; 340: 25I. doi: I0.I I36/bmj.b5569 metastatic disease. In parallel, novel molecular markers of disease progression and response to therapy must be defined through the assessment of tumour genetic signatures. We believe that significant advances will be made through research into the role of chronic inflammation in the early development, growth and spread of lung cancer and that this should be a major focus for the next decade. Ultimately, it is hoped that lung cancer will become, for the majority of patients, a disease with extended periods of remission or even cure after therapy.

18 Benowitz NL. Nicotine addiction. N Engl J Med 2010; 362:2295303. doi: I0.1056/NEJMra0809890

19 Doggrell SA. Partial agonism at nicotinic receptors with varenicline - a new approach to smoking cessation. Expert Opin Pharmacother 2006; 7:2599-603. doi:10.15 I7//4656566.7.18.2599

20 Gonzales D, Rennard SI, Nides M et al.Varenicline, an $\alpha 4 \beta 2$ nicotine acetylcholine receptor partial agonist, versus sustained-release bupropion and placebo for smoking cessation - a randomized controlled trial.JAMA 2006; 296:47-55. doi:I0.100I/jama.296.1.47

21 Tonstad S, Tennesen P, Hajek P et al. Effect of maintenance therapy with varenicline on smoking cessation - a randomized controlled trial. JAMA 2006; 296:64-7I. doi: 10.1001/jama.296.1.64

22 Kanner RE, Connett JE, Williams DE et al. Effects of randomized assignment to a smoking cessation intervention and changes in smoking habits on respiratory symptoms in smokers with early chronic obstructive pulmonary disease: the Lung Health Study. Am J Med 1999; 106:4I0-6. doi:I0.1016/S0002-9343(99)00056-X

23 Bierut LJ. Convergence of genetic findings for nicotine dependence and smoking related diseases with chromosome 15q24-25. Trends Pharmacol Sci 2010; 31:46-5I. doi:10.1016/j.tips.2009.10.004

24 Wakelee HA, Chang ET, Gomez SL et al. Lung cancer incidence in never smokers. J Clin Oncol 2007; 25:472-8. doi:10.1200/ JCO.2006.07.2983

25 Coté ML, Kardia SL, Wenzlaff AS et al. Risk of lung cancer among white and black relatives of individuals with early-onset lung cancer. JAMA 2005; 293:3036-42. doi:10.1001/jama.293.24.3036

26 Bailey-Wilson JE, Amos $\mathrm{Cl}$, Pinney SM et al. A major lung cancer susceptibility locus maps to chromosome 6q23-25. Am J Hum Genet 2004; 75:460-74. doi:10.1086/423857

27 You M,Wang D, Liu P et al. Fine mapping of chromosome 6q23-25 region in familial lung cancer families reveals RGSI7 as a likely candidate gene. Clin Cancer Res 2009; I 5:2666-74. doi: I0. I I 58/I0780432.CCR-08-2335

28 Wang Y, Broderick P, Webb E et al. Common 5pI5.33 and 6p21.33 variants influence lung cancer risk. Nat Genet 2008; 40:1407-9. doi:10.1038/ng.273

29 Amos $\mathrm{Cl}, \mathrm{Wu}$ X, Broderick P et al. Genome-wide association scan of tag SNPs identifi es a susceptibility locus for lung cancer at I5q25. I. Nat Genet 2008; 40:616-22. doi:10.1038/ng. 109

30 Hung RJ, McKay JD, Gaborieau V et al. A susceptibility locus for lung cancer maps to nicotinic acetylcholine receptor subunit genes on 15q25. Nature 2008; 452:633-7. doi:10.1038/nature06885

31 Brennan P, Hainaut P and Boffetta P. Genetics of lung-cancer susceptibility. Lancet Oncol 20I I; I2:399-408. doi:I0.1016/SI4702045(10)70126-I

32 Pleasance ED, Stephens PJ, O'Meara S et al. A small-cell lung cancer genome with complex signatures of tobacco exposure. Nature 2010; 463:I84-90. doi:10.1038/nature08629

33 Lee W, Jiang Z, Liu J et al. The mutation spectrum revealed by paired genome sequences from a lung cancer patient. Nature 20 I0; 465:473-7. doi:10.1038/nature09004

34 Humphrey LL, Teutsch S, Johnson M et al. Lung cancer screening with sputum cytologic examination, chest radiography, and 
computed tomography: an update for the U.S. Preventive Services Task Force. Ann Intern Med 2004; 140:740-53.

35 Nawa T, Nakagawa T, Kusano $\mathrm{S}$ et al. Lung cancer screening using low-dose spiral CT: results of baseline and I-year follow-up studies. Chest 2002; I22: I5-20. doi: I0.1378/chest. I22.I.I5

36 Sone S, Li F, Yang ZG, Honda T et al. Results of three-year mass screening programme for lung cancer using mobile low-dose spira computed tomography scanner. $\mathrm{Br} J$ Cancer 200I; 84:25-32. doi: I0.1054/bjoc.2000.I53I

37 Henschke $\mathrm{Cl}$, Yankelevitz DF, Libby DM et al. Early lung cancer action project: annual screening using single-slice helical CT. Ann NY Acad Sci 200 I; 952: I24-34. doi:I0. I I I I/j. I749-6632.200 I.tb02733.x

38 Swensen SJ, Jett JR, Sloan JA et al. Screening for lung cancer with low-dose spiral computed tomography. Am J Respir Crit Care Med 2002; 165:508-13.

39 Aberle DR, Berg CD, Black WC et al.The National Lung Screening Trial: overview and study design. Radiology 20II; 258:243-53. doi: I0.I|48/radiol. 10091808

40 Pedersen $\mathrm{JH}$, Ashraf $\mathrm{H}$, Dirksen A et al. The Danish randomized lung cancer CT screening trial - overall design and results of the prevalence round. J Thorac Oncol 2009; 4:608-I4. doi:I0.I097| JTO.0b0I3e318Ia0d98f

4I Lopes Pegna A, Picozzi G, Mascalchi $M$ et al. Design, recruitment and baseline results of the ITALUNG trial for lung cancer screening with low-dose CT. Lung Cancer 2009; 64:34-40. doi:I0.1016/j.lungcan.2008.07.003

42 Montes U, Seijo LM, Campo A et al. Factors determining early adherence to a lung cancer screening protocol. Eur Respir J 2007 30:532-7. doi:10.1 183/09031936.00143206

43 MacMahon H, Austin JHM, Gamsu G et al. Guidelines for management of small pulmonary nodules detected on CT scans: a statement from the Fleischner Society. Radiology 2005; 237:395400. doi: I0.1 | 48/radiol.237204 I887

44 Cronin P, Dwamena BA, Kelly AM et al. Solitary Pulmonary nodules: meta-analytic comparison of cross-sectional imaging modalities for diagnosis of malignancy. Radiology 2008; 246:772-82. doi: I0.1 |48/radiol.2463062 |48

45 Croswell JM, Ransohoff DF, Kramer BS. Principles of cancer screening: lessons from history and study design issues. Semin Oncol 2010; 37:202-I5. doi:I0.1053/j.seminoncol.2010.05.006

46 Baldwin DR, Duffy SW, Wald NJ et al. UK Lung Screen (UKLS) nodule management protocol: modelling of a single screen randomised controlled trial of low-dose CT screening for lung cancer. Thorax 201 I; 66:308-13. doi:I0.1 I36/thx.20I0.I52066

47 Detterbeck FC, Boffa DJ, Tanoue LT. The new lung cancer staging system. Chest 2009; I36;260-7I. doi: I0.1378/chest.08-0978

48 Ravenel JG, Mohammed TL, Movsas B et al. ACR Appropriateness Criteria ${ }^{\circledR}$ noninvasive clinical staging of bronchogenic carcinoma. J Thorac Imaging 20I0; 25:WI07-II. doi:I0.1097/ RTI.0b0I3e3I8If5le7f

49 Rintoul RC, Skwarski KM, Murchison JT et al. Endobronchial and endoscopic ultrasound-guided real-time fine-needle aspiration for mediastinal staging. Eur Respir J 2005; 25:4 I6-2 I. doi: I 0. I I83/0903 1936.05.00095404

50 Annema JT, van Meerbeeck JP, Rintoul RC et al. Mediastinoscopy vs endosonography for mediastinal nodal staging of lung cancer: a randomized trial. JAMA 20I0; 304:2245-52. doi:10.100I/ jama.2010.1705

5I Lawson MH, Rassl DM, Cummings NM et al. Tissue banking of diagnostic lung cancer biopsies for extraction of high quality RNA. J Thorac Oncol 2010; 5:956-63.

52 Smolle-juettner FM, Maier A, Lindenmann J et al. Resection in stage I/II non-small cell lung cancer. Front Radiat Ther Oncol 20 I 0; 42:7 I-7. doi: $10.1159 / 000262462$

53 Jeremic B, Casas F, Wang L, et al. Radiation therapy for early stage (I/II) non-small cell lung cancer. Front Radiat Ther Oncol 2010 42:87-93. doi:10.1159/000262464

54 Pignon JP, Tribodet H, Scagliotti GV et al. Lung adjuvant cisplatin evaluation: a pooled analysis by the LACE Collaborative Group. J Clin Oncol 2008; 26:3552-9. doi:I0.1200/JCO.2007.13.9030
55 Mayor S. NICE issues guidance for diagnosis and treatment of lung cancer. BMJ 2005; 330:439. doi:I0.I 136/bmj.330.7489.439-b

56 PORT Meta-analysis Trialists Group. Postoperative radiotherapy for non-small cell lung cancer. Cochrane Database Syst Rev 2005; 2:CD002I42.

57 Lally BE, Zelterman D, Colasanto JM et al. Postoperative radiotherapy for stage II or III non-small cell lung cancer using the surveillance, epidemiology, and end results database. J Clin Oncol 2006; 24:2998-3006. doi:I0.1200/JCO.2005.04.6II0

58 Sawyer TE, Bonner JA, Gould PM et al. The impact of surgical adjuvant thoracic radiation therapy for patients with nonsmall cell lung carcinoma with ipsilateral mediastinal lymph node involvement. Cancer 1997; 80:1399-408. doi:10.1002/(SICI) I0970I42(I9971015)80:8<1399::AID-CNCR6>3.0.CO;2-A

59 Le Péchoux $C$. Role of postoperative radiotherapy in resected non-small cell lung cancer: a reassessment based on new data. Oncologist 20I I; epub ahead of print Mar 4.

60 Emami B, Kaiser L, Simpson J et al. Postoperative radiation therapy in non-small cell lung cancer. Am J Clin Oncol 1997; 20:44I-8. doi:10.1097/00000421-199710000-00003

6I The Lung Cancer Study Group. The benefit of adjuvant treatment for resected locally advanced non-small-cell lung cancer. J Clin Oncol 1988; 6:9-17.

62 Non-small Cell Lung Cancer Collaborative Group. Chemotherapy for non-small cell lung cancer. Cochrane Database Syst Rev 2000; 2:CD002I39.

63 Keller SM, Adak S, Wagner $\mathrm{H}$ et al. A randomized trial of postoperative adjuvant therapy in patients with completely resected stage II or IIIA non-small-cell lung cancer. N Engl J Med 2000; 343:I217-22. doi:10.1056/NEJM20001026343। 703

64 NSCLC Collaborative Group. Chemotherapy in non-small cell lung cancer: a meta-analysis using updated data on individual patients from 52 randomised clinical trials. BMJ 1995; 311:899-909.

65 O’Rourke N, Roqué i Figuls M, Farré Bernadó N et al. Concurrent chemoradiotherapy in non-small cell lung cancer. Cochrane Database Syst Rev 2010; 6:CD002I40.

$66 \mathrm{Kim}$ TE, Murren JR. Therapy for stage IIIB and stage IV non-small cell lung cancer. Clin Chest Med 2002; 23:209-24. doi:10.1016/S0272523I (03)00069-8

67 NSCLC Meta-Analyses Collaborative Group. Chemotherapy in addition to supportive care improves survival in advanced nonsmall-cell lung cancer: a systematic review and meta-analysis of individual patient data from 16 randomized controlled trials. J Clin Oncol 2008; 26:46I7-25. doi: I0.I200/JCO.2008.17.7I62

68 Scagliotti GV, Parikh P, von Pawel J et al. Phase III study comparing cisplatin plus gemcitabine with cisplatin plus pemetrexed in chemotherapy-naive patients with advanced-stage non-small-cell lung cancer. J Clin Oncol 2008; 26:3543-5I. doi:10.1200/ JCO.2007.15.0375

69 Fossella FV, DeVore R, Kerr RN et al. Randomized phase III trial of docetaxel versus vinorelbine or ifosfamide in patients with advanced non-small-cell lung cancer previously treated with platinumcontaining chemotherapy regimens. J Clin Oncol 2000; 18:2354-62.

70 Dancey J, Shepherd FA, Gralla RJ et al. Quality of life assessment of second-line docetaxel versus best supportive care in patients with non-small cell lung cancer previously treated with platinum-based chemotherapy: results of a prospective, randomized phase III trial. Lung Cancer 2004; 43: I83-94. doi: 10.10 I6/j.lungcan.2003.09.00I

7I Hanna N, Shepherd FA, Fossella FV et al. Randomized phase III trial of pemetrexed versus docetaxel in patients with non-small-cell lung cancer previously treated with chemotherapy. J Clin Oncol 2004; 22:I589-97. doi:10.1200/JCO.2004.08.163

72 Fidias PM, Dakhil SR, Lyss AP et al. Phase III study of immediate compared with delayed docetaxel after front-line therapy with gemcitabine plus carboplatin in advanced non-small-cell lung cancer. J Clin Oncol 2009; 27:59I-98. doi:I0.I200/JCO.2008.I7.1405

73 Ciuleanu T, Brodowicz T, Zielinski C et al. Maintenance pemetrexed plus best supportive care versus placebo plus best supportive care for non-small cell lung cancer: a randomised, double-blind, phase 3 study. Lancet 2009; 374:1432-40. doi:I0.1016/S0I40-6736(09)6/497-5 
74 Hodkinson PS, Mackinnon A, Sethi T. Targeting growth factors in lung cancer. Chest 2008; 133:1209-16. doi:10.1378/chest.07-2680

75 Harris TJ, McCormick F. The molecular pathology of cancer. Nat Rev Clin Oncol 2010; 7:25I-65. doi:10.1038/nrclinonc.2010.41

76 Ciardiello F, Tortora G. A novel approach in the treatment of cancer: targeting the epidermal growth factor receptor. Clin Cancer Res 200I; 7:2958-70.

77 Meert AP, Martin B, Delmotte $P$ et al.The role of EGF-R expression on patient survival in lung cancer: a systematic review with metaanalysis. Eur Respir J 2002; 20:975-81. doi:10.1 183/09031936.02.00 296502

78 Ettinger DS. Emerging profile of cetuximab in non-small cell lung cancer. Lung Cancer 2010; 68:332-7. doi:I0.1016/j.lungcan.2009.07.012

79 Pirker R, Pereira JR, Szczesna A et al. Cetuximab plus chemotherapy in patients with advanced non-small-cell lung cancer (FLEX): an open-label randomised phase III trial. Lancet 2009; 373:I525-3I. doi: I0.10I6/S0I40-6736(09)60569-9

80 Ibrahim EM, Abouelkhair KM, Al-Masri OA et al. Cetuximab-based therapy is effective in chemotherapy-naïve patients with advanced and metastatic non-small-cell lung cancer: a meta-analysis of randomized controlled trials. Lung 20I I; epub ahead of print Mar 20.

81 Joerger M, Matter-Walstra K, Früh $M$ et al. Addition of cetuximab to first-line chemotherapy in patients with advanced non-small-cell lung cancer: a cost-utility analysis. Ann Oncol 20II; 22:567-74. doi: 10.1093/annonc/mdq43 I

82 Fukuoka M,Yano S, Giaccone G et al. Multi-institutional randomized phase II trial of gefitinib for previously treated patients with advanced non-small-cell lung cancer (The IDEAL I Trial) [corrected]. J Clin Oncol 2003; 21:2237-46. doi: I0.1200/JCO.2003.10.038

83 Kris MG, Natale RB, Herbst RS et al. Efficacy of gefitinib, an inhibitor of the epidermal growth factor receptor tyrosine kinase, in symptomatic patients with non-small cell lung cancer: a randomized trial. JAMA 2003; 290:2149-58. doi:10.1001/ jama.290.16.2149

84 Crinò L, Cappuzzo F, Zatloukal P et al. Gefitinib versus vinorelbine in chemotherapy-naive elderly patients with advanced non-smallcell lung cancer (INVITE): a randomized, phase II study.J Clin Oncol 2008; 26:4253-60. doi:I0.I200/JCO.2007.I5.0672

85 Thatcher N, Chang A, Parikh P et al. Gefitinib plus best supportive care in previously treated patients with refractory advanced nonsmall-cell lung cancer: results from a randomised, placebocontrolled, multicentre study (Iressa Survival Evaluation in Lung Cancer). Lancet 2005; 366:1527-37. doi:10.1016/S01406736(05)67625-8

86 Herbst RS, Giaccone G, Schiller JH et al. Gefitinib in combination with paclitaxel and carboplatin in advanced non-small-cell lung cancer: a phase III trial - INTACT 2. J Clin Oncol 2004; 22:785-94. doi:10.1200/JCO.2004.07.2I5

87 Giaccone G, Herbst RS, Manegold C et al. Gefitinib in combination with gemcitabine and cisplatin in advanced non-small-cell lung cancer: a phase III trial - INTACT I.J Clin Oncol 2004; 22:777-84. doi:I0.1200/JCO.2004.08.00I

$88 \mathrm{Kim}$ ES, Hirsh V, Mok T et al. Gefitinib versus docetaxel in previously treated non-small-cell lung cancer (INTEREST): a randomised phase III trial. Lancet 2008; 372:1809-18. doi:10.1016/ SOI40-6736(08)6 I758-4

89 Shepherd FA, Rodrigues Pereira J, Ciuleanu T et al. Erlotinib in previously treated non-small-cell lung cancer. N Engl J Med 2005; 353: I23-32. doi: I0.1056/NEJMoa050753

90 Haas-Kogan DA, Prados MD, Lamborn KR et al. Biomarkers to predict response to epidermal growth factor receptor inhibitors. Cell Cycle 2005; 4: I369-72. doi: 10.416I/cc.4.10.2105

9I Paez JG, Janne PA, Lee JC et al. EGFR mutations in lung cancer: correlation with clinical response to gefitinib therapy. Science 2004; 304:|497-500. doi: 10.1 |26/science. 10993 | 4

92 Pircher A, Ploner F, Popper $\mathrm{H}$ et al. Rationale of a relaunch of gefitinib in Caucasian non-small cell lung cancer patients. Lung Cancer 2010; 69:265-71. doi:10.1016/j.lungcan.2010.01.017
93 Mok TS, Wu YL, Thongprasert S et al. Gefitinib or carboplatinpaclitaxel in pulmonary adenocarcinoma. N Engl J Med 2009; 361:947-57. doi:10.1056/NEJMoa0810699

94 Giaccone G, Wang Y. Strategies for overcoming resistance to EGFR family tyrosine kinase inhibitors. Cancer Treat Rev 20I I; epub ahead of print Feb 28.

95 Bergers G, Benjamin LE. Tumorigenesis and the angiogenic switch. Nat Rev Cancer 2003; 3:40I-10. doi:10.1038/nrcl093

96 Bremnes RM, Camps C, Sirera R. Angiogenesis in non-small cell lung cancer: the prognostic impact of neoangiogenesis and the cytokines VEGF and bFGF in tumours and blood. Lung Cancer 2006; 5I:|43-58. doi:10.1016/j.lungcan.2005.09.005

97 Reck M, von Pawel J, Zatloukal P et al. Phase III trial of cisplatin plus gemcitabine with either placebo or bevacizumab as first-line therapy for nonsquamous non-small-cell lung cancer. J Clin Oncol 2009; 27:I227-34. doi:I0.1200/JCO.2007.14.5466

98 Sandler A, Gray R, Perry MC et al. Paclitaxel-carboplatin alone or with bevacizumab for non-small-cell lung cancer. N Engl J Med 2006; 355:2542-50. doi:I0.1056/NEJMoa06I884

99 Ramalingam SS, Dahlberg SE, Langer CJ et al. Outcomes for elderly, advanced-stage non small-cell lung cancer patients treated with bevacizumab in combination with carboplatin and paclitaxel: analysis of Eastern Cooperative Oncology Group Trial 4599. J Clin Oncol 2008; 26:60-5. doi:I0.I 200/JCO.2007.|3.I|44

100 Natale RB. Dual targeting of the vascular endothelial growth factor receptor and epidermal growth factor receptor pathways with vandetinib (ZD6474) in patients with advanced or metastatic nonsmall cell lung cancer. J Thoracic Oncol 2008; 3(Suppl 2):SI28-30. doi:10.1097/JTO.0b013e318174e95a

I0I Lee G, Walser TC, Dubinett SM. Chronic inflammation, chronic obstructive pulmonary disease, and lung cancer. Curr Opin Pulm Med 2009; I5:303-7. doi:I 0. I097/MCP.0b0 I 3e32832c975a

102 Kiri VA, Fabbri LM, Davis KJ et al. Inhaled corticosteroids and risk of lung cancer among COPD patients who quit smoking. Respir Med 2009; 103:85-90. doi:10.1016/j.rmed.2008.07.024

103 Yu YY, Pinsky PF, Caporaso NE et al. Lung cancer risk following detection of pulmonary scarring by chest radiography in the Prostate, Lung, Colorectal, and Ovarian Cancer Screening Trial. Arch Intern Med 2008; 168:2326-32. doi:10.1001/archinte.168.21.2326

104 Chaturvedi AK, Caporaso NE, Katki HA et al. C-reactive protein and risk of lung cancer.J Clin Oncol 2010; 28:2719-26. doi:I0.1200/ JCO.2009.27.0454

105 Moghaddam SJ, Li H, Cho SN et al. Promotion of lung carcinogenesis by chronic obstructive pulmonary disease-like airway inflammation in a K-ras-induced mouse model. Am J Respir Cell Mol Biol 2009; 40:443-53. doi:10.1165/rcmb.2008-01980C

106 Houghton AM, Mouded M, Shapiro SD. Common origins of lung cancer and COPD. Nat Med 2008; 14:1023-4. doi:10.1038/ nm I008-1023

107 Takahashi H, Ogata H, Nishigaki R et al. Tobacco smoke promotes lung tumorigenesis by triggering IKK $\beta$ and JNKI dependent inflammation. Cancer Cell 2010; 17:89. doi:10.1016/j. ccr.2009.12.008

108 Bremnes RM, Al-Shibli K, Donnem T et al. The role of tumorinfiltrating immune cells and chronic inflammation at the tumor site on cancer development, progression, and prognosis: emphasis on non-small cell lung cancer. J Thorac Oncol 2010; epub ahead of print Dec 17.

109 Dai F, Liu L, Che G et al. The number and microlocalization of tumor-associated immune cells are associated with patient's survival time in non-small cell lung cancer. BMC Cancer 2010; 10:220. doi: I0. I I86/I47I-2407-10-220

I I 0 Rauh MJ, Ho V, Pereira C et al. SHIP represses the generation of alternatively activated macrophages. Immunity 2005; 23:36I-74. doi:I0.10I6/j.immuni.2005.09.003 